\title{
EXPLORING CONTEMPORARY ANTHROPOLOGICAL THEORY: CAN WE USE POSTHUMANISM TO RECONCEPTUALISE THE DISABLED BODY?
}

\author{
Hannah Gibson
}

\begin{abstract}
Posthumanism is an umbrella term signalling theoretical approaches that endeavour to challenge pervasive human/non-human, normal/abnormal, organic/man-made binaries. To explore the value of posthumanism for disability studies, this piece interrogates Latour's Actor Network Theory and Haraway's Cyborg Theory. Both scholars provide innovative ways of reconceptualising how bodies are intimately connected and shaped by technology once we move beyond a purely human-centred mode of understanding the world. I seek to provoke the nuances of each paradigm by applying them to three distinct cases of people who are classified disabled by society and connect differently with technology. Haraway celebrates expansion of subjectivity and hybridity, yet her cyborg imagery better articulates those bodies which are augmented through personal choice rather than circumstance or dependency. On the other hand, a Latourian framework simultaneously rejects preconceptions of what disability is whilst allowing new insights to emerge without denying the possibility of existing inequalities or oppression. This ultimately offers more value to disability studies and anthropology of disability.
\end{abstract}

Keywords: Posthumanism, disability, cyborg theory, Actor network theory

\section{INTRODUCTION}

The philosophers have only interpreted the world, in various ways: the point, however, is to change it (Karl Marx 1976).

From a Western humanistic lens, which equates humanness with wholeness and health, disabled people ${ }^{1}$ are often perceived as inferior to those who are 'able-bodied. Thus by breaking down categories that have traditionally separated those deemed normal/abnormal, posthumanism should be of value to 
disability studies. To explore this, I have chosen two theorists whose work possibly sits within a posthumanism arena. They are social-feminist Donna Haraway and her cyborg theory and sociologist Bruno Latour and his Actor Network Theory (ANT). Although neither is known for providing theoretical contributions within the topic of disability, there is space for their entry into the discussion. By celebrating difference and hybridity, Haraway extends our conceptions of how humans are intimately connected to technology. Yet, whilst valuable, her theory is best suited to people who choose to change and augment their bodies, particularly in an imaginative way. This creates new categories of difference whereby not all disabled people would be welcomed into Haraway's cyborg world, especially the economically underprivileged. Additionally, different issues of inclusion arise particularly when technology is used by the disabled in order to be accepted and treated as able-bodied. This is where Latour's theory is more applicable. By rejecting any pre-existing idea of what disability is, dichotomies of normal/abnormal lose their value, which allows for fresh and new discussions to take place without rejecting the possibility of inequality. Further, against critiques that Latour's theory is apolitical, the application of his theory does not remain neutral. Instead, presuppositions that engage with power dynamics emerge if they exist within networks, without reinforcing the inequalities that bind disabled people to begin with. Ultimately, whilst Haraway's cyborg imagery reconstructs a humanistic dialogue of inferiority towards less-able bodied people, Latour demonstrates that disability can be viewed without a preconceived stigma of difference.

In order to offer context to the discussion, the topic of disability is briefly outlined within a framework of how traditional humanistic discourses have categorised those deemed different. The main concepts of posthuman thought question the very foundations upon which humanism has been constructed over several episteme. To explore the practicality of Haraway and Latour, three distinct case studies will firstly show the various types of bodies society classifies as disabled. Deliberately chosen because they all engage with technology differently, the first of these is Neil Harbisson who is completely colour blind and has been implanted with a device which is connected to an external attachment, allowing him to register colour as sound. Next are Aimee Mullins and Oscar Pistorius who are both double amputee professional athletes. Finally, I look at Folole Muliaga from New Zealand, who died after the power to her house disabled the oxygen purifier she needed to be able to breathe. Since neither Haraway nor Latour explicitly write about disability, after their concepts are summarised I will briefly apply them to these three cases. This will help in turn to interrogate the theories to explore the applicability of their concepts for disability studies. In consideration of Marx's argument that interpreting the 
world is not enough, his perspective is one that challenges whether theories can actually be practical. Comparing Latour and Haraway demonstrates that whilst Haraway's perspective is helpful to reconceptualise the relationship humans have to technology, cyborg imagery can be humanistic in orientation. Latour instead embraces posthuman thought more fully, seeking to see how the world is made once he makes humanistic categorising redundant. In providing a unique lens through which to view the world in its complexities, Latour's theory and methodology are ultimately more useful for the topic of disability.

According to Crow $(1996,3)$, 'while impairment is the functional limitation(s) which affect a person's body [or mind], disability is the loss or limitation of opportunities resulting from direct and indirect discrimination'. Although there is some divergence ${ }^{2}$, disability studies scholars largely agree with Crow in the use of 'disability' as a way to describe a group of people who live with impairments and are subsequently dis-abled by society (Brisenden 1986; Crow 1996, 207; Ferguson and Nusbaum 2012; Goodley 2011; Linton 1998; Oliver 1993; Shakespeare 1998). This perspective belongs to a social model of disability which emerged within disability studies in the 1990s to challenge purely medical or moral discourses about the body that place the culpability of any physical, sensory, or mental impairment on the individual (Goodley 2011, 6). Rather than assuming to know how those who live with sensory, physical or mental impairments conceptualise their experiences, I propose, alongside Michalko $(2002,168)$ that disability is a framework of differential analysis, as something to think with, rather than about, which has the potential to disrupt negative perceptions. In doing this, disability becomes a 'fluid and shifting set of conditions' (Shilrick and Price 1996, 93), as opposed to a static and devaluing definition.

Briefly, posthumanism is a theoretical approach that emerged in the $1990 \mathrm{os}$ with roots traced through the fields of philosophy (Foucault 1970; Wolf 2010) feminism, (Braidotti 2006; 2013; Haraway 2010; Thacker 2003) theological anthropology (Thweatt-Bates 2012); and science and technology studies (Latour 1993). Instead of being a theoretical approach that is anti-human ${ }^{3}$, posthumanism challenges the prominent place humans have held within Western configurations of knowledge since the Industrial Revolution (Wolfe 2010, xxv). According to Braidotti $(2013,15,24)$, within this framework emerged the Western concept of the human; namely a healthy, rational, and white male, 'an ideal of bodily perfection. Through the lens of posthumanism, this closed notion of a 'whole human' being transcendental, universal, and timeless is disengaged with people living with impairments who have traditionally been placed into the category of the 'abnormal,' 'not fully human', 'quasi human', and ultimately 
an 'Other' (Campbell 2009, 67; Swartz and Watermeyer 2008, 187). Further, the category or label 'disabled' centres around a myth that being disabled or ablebodied, male or female, different or normal is a product of our birth (Herndl $2002,153)$. This distinction of what is acceptable or not is human-made and creates the exclusion people believe is natural.

Thweatt-Bates $(2013,1)$ contends that posthuman is an umbrella term that covers a diverse group of concepts, including genetically enhanced persons and the amalgamation of the artificial with the organic, chimeras and cyborgs (a hybrid of machine and human). In this sense, to be 'post-human' is not a definable state of being ${ }^{4}$ but an expansion of how we have previously conceptualised the human. It is a provocation of diverseness, and celebration of plurality. I explore the concept of the posthuman as 'a new and growing appreciation for the plasticity and flexibility of "human nature" spurred by discoveries in biotechnology and virtual, information and communication technologies' (Thweatt-Bates 2013, 1). From this position, posthumanism should be a valuable paradigm to engage with disability studies because it aims to reconceptualise how we view the human when we decentralise the humanistic version from their place of superiority above all other living and non-living things (Wolfe 2010, xii).

Haraway and Latour are two distinctly different theorists who offer valuable theoretical perspectives. In order to interrogate both it is important to first briefly apply them to the following three cases, which exemplify the variety of people living with different impairments that might be perceived as disabled. By doing this it will then be possible to use the cases to uncover the implications Haraway and Latour offer for disability studies.

\section{CASE ONE}

Spanish artist Neil Harbisson was born with achromatopsia, which means he is completely colour blind and can only see the world around him in shades of grey (Harbisson 2012, 50). He refers to his own self as a cyborg, whereby he has a device attached to his head that resembles a third electronic eye. It is a part of his flesh and cannot be easily removed, with Harbisson believing that rather than being a technological aid, it is a part of him (Harbisson 2012, 50). This external eye detects the hues, saturation and light that colour is made up of, and translates this into sound frequency through a chip that has been transplanted into the bone at the back of Harbisson's head (Figure 1). Basically, Harbisson hears colour, with each hue and saturation level converting into a different note, so he is able to relate to and recognise colour in ways that most 
people are incapable of. This new ability could be likened to synaesthesia, a neurological phenomenon where stimulation of one sensory pathway leads to the involuntary stimulation of a second one. The electronic eye appears to give Harbisson 'super-human' capabilities, for example, he can see colour that is invisible, such as ultraviolet, making him hyper-sensitive to, and in-tune with, the environment around him.

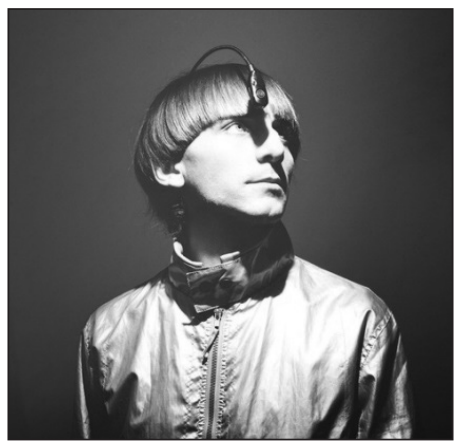

Figure 1. Neil Harbisson

(Source: http://pioneers.io/wp-content/uploads/2013/o7/neil_harbisson_cyborg.jpg)

CASE TWO

Professional athletes Aimee Mullins and Oscar Pistorius were born without fibula bones, had both legs amputated at birth (Griggs 2009,30), and run with carbon fibre blades called cheetah legs. Although the Paralympics have had contenders who have used 'cheetah legs' for over 20 years, these two Paralympians are explicit examples of people who rework traditional categories of 'normal/abnormal.' The photographs (Figure 2) of Mullins and Pistorius illustrate how the shaping and honing of their bodies until they are in peak physical condition has attracted media portrayals of them as sexy and appealing rather than, or as well as, disabled. This indicates that regardless of whether they are able-bodied or double amputees, the body of athletes are regarded as visually pleasing (Swartz and Watermeyer 2008, 189).

In addition to her social status as a sports icon, holding world records in the 1996 Paralympics whilst running on her sprinting cheetah legs (Vainshtein 2012, 149), Mullins has pushed the boundaries of what is traditionally considered beautiful. For example, she has been included in a variety of fashion magazines that appear to celebrate her diversity as well as her physical attractiveness. Mullins sees herself as someone who has decided to augment her 
body rather than using prosthetics to correct her disability. Oscar Pistorius, also known as blade runner and 'the fastest man on no legs' has competed and won medals in both the 2005 Paralympics in Manchester, and again in Beijing in 2008 (Silvers 2011, 35). His goal has always been to compete against ablebodied people, and after racing against 'normal' runners and qualifying, his presence in the 2012 Olympic Games caused worldwide interest. Much of it is reflective of the worries that he has transgressed categories from being disabled to actively engaging in 'able-bodied' sporting categories (Longman, Kiefer and Robinson 2012, 8). These include the sceptics who believe that if Pistorius were to be as fast as an able-bodied athlete, his eligibility may be revoked, insinuating that he can run as long as he does not win (Crincoli 2011, 135).
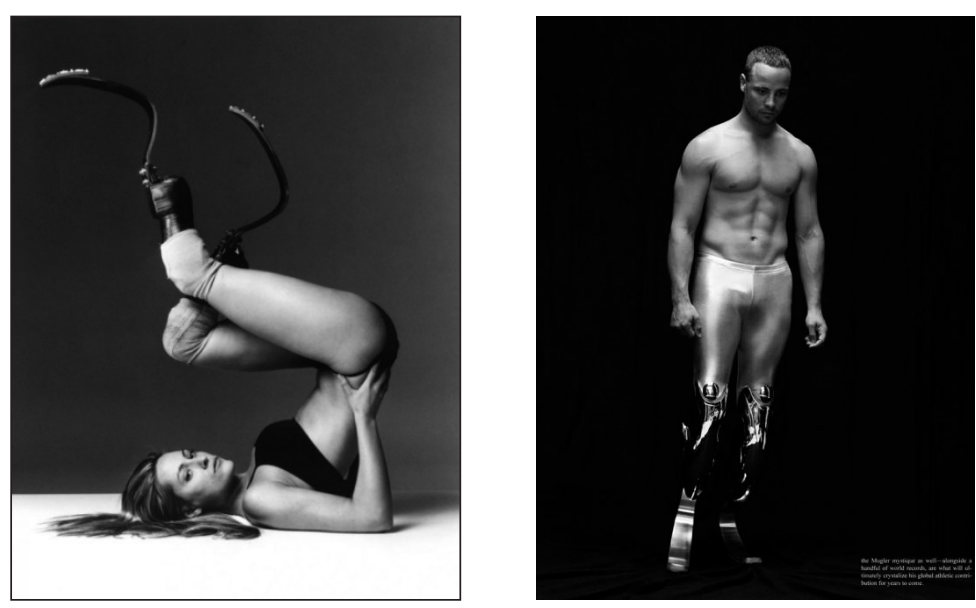

Figure 2. Aimee Mullins (Left) and Oscar Pistorius (Right)

(Sources: http://dismagazine.com/uploads/2012/o2/aimee-mullins.jpg \& http://www.malecelebnews.com/wp-content/images/2011/10/oscar-pistoriustetsuharu-kubota-homotography-3.jpg)

\section{CASE THREE}

Folole Muliaga was a 44 year old mother of four residing in Auckland, New Zealand, and suffered from a heart and lung condition (not from birth) that caused breathing difficulties and required her to use an oxygen purifier (Figure 3). When her family were unable to pay their electricity bill due to loss of income when Muliaga could no longer work, the power company disconnected the electricity. Her life depended upon being able to use her oxygen purifier 
that needed power to run, and she sadly died within two hours of the disconnection (The NZ Herald 2007). The reason I have chosen this woman as the third case study is because, unlike Harbisson, Mullins and Pistorius, Muliaga had a physical dependency on technology that she needed to access to stay alive. She had no special, marketable talent or rare condition but remained unknown until her death. She is what I term a forgettable disabled person's, one of the many people with conditions or disabilities who are dependent on devices to survive and who are categorised as Others. More often than not, they do not have a good income to help with their bills or give them state of the art, expensive technology.

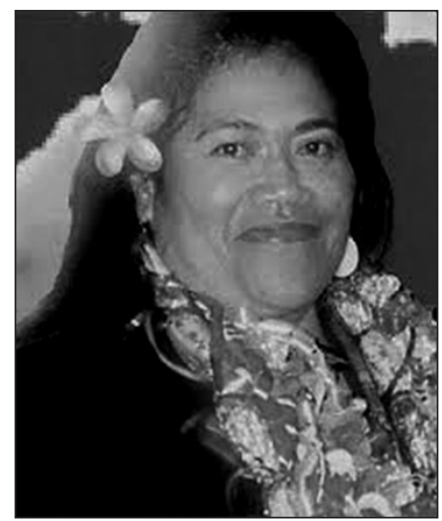

Figure 3. Folole Muliaga

(Source: http://www.stuff.co.nz/the-press/640974/Cutting-power-a-factor-in-Muliaga -death)

Donna Haraway, a socialist-feminist and historian of science with a background in biology and philosophy, offers a persuasive theoretical lens. She explores the way the social world and categories within it have been created by natural and social scientists that have produced oppressive discourses that place the white and rational male above others, including females and nonhumans. Although not a self-named posthumanist theorist, her concepts and contributions can be linked quite clearly to this paradigm because she rejects the humanistic tendency of placing humans as a central nexus.

In Cyborg Manifesto, Haraway $(1991,45,149)$ argues that in the highly technological world that we live in, we are all cyborgs to various degrees. By this she 
means a cybernetic organism, a fusion of organism and machine, and part of social reality and fiction at the same time. Such a concept of a cyborg may seem mythical, especially when we consider science fiction movies that convey an idea of a creature that appears to be made of fantasy. However, Haraway is both signalling the physical reality of our relationship with technology, as well as using the cyborg image as a metaphor to challenge pervasive dualisms of humans/non-humans, organic/inorganic, man-made/flesh (Haraway 1991, 151). By placing our subjectivity within the context of the technoculture we live in, Haraway $(1991,176)$ argues that it has become increasingly difficult to imagine where our bodies begin and where they end, thus calling into question any concept of the human body as simply 'human'. The cyborg imagery 'comes to the forefront in discussion of the posthuman because it is such a potent symbol of the difference affected by technology physically intertwined with the nonhuman, the organic with the mechanical' (Thweatt-Bates 2012, 15). Haraway suggests we should seek pleasure in being different, in messing with categories that under a humanistic regime created limitations on what was normal or abnormal. This is where imagination is encouraged and celebrated.

\section{APPLICATION OF HARAWAY}

Haraway $(1991,150,178)$ states that modern medicine is full of cyborgs, of couplings between organism and machine', and that people who are severely handicapped have an intense experience of complex hybridisation because of their reliance on technology. Such a hybridity, to use Haraway's terms, would seem like an interesting avenue to explore, yet this is the only mention she gives this subject. Application of her theory within disability studies is also largely absent (Reeve 2012, 91), and within social science studies, Quinlin and Bates $(2009,51)$ argue that cyborg discussions are mostly concerned with fully functioning and healthy bodies. Therefore, the only way to discern what implications Haraway's perspective has for disability studies is to apply it. Thus, when Haraway contends we are all cyborgs, instead of questioning whether a fusion of fact and fiction begins with a body that is fully human and capable, attention must be brought to whether inferior cyborgs can exist within this imagery.

To begin, Haraway $(1991,178)$ poses the question, 'why should our bodies end at the skin?' Harbisson's case is a good example, whereby his subjectivity is inexplicably intertwined with his relationship to the mechanical eye, producing a bond between machine and technology that is a core part of Haraway's $(1991,180)$ imagery of the cyborg. For example, Harbisson's physical body itself transcends and blurs boundaries such as organic/inorganic, flesh/man-made 
through his existence of both worlds at once. Although he remains colour blind, technology has reconfigured him from being someone with a disability into someone with 'super'-abilities. He now possesses capacities for understanding colour in ways unimaginable to many. It is here that we can see how constructions by communications sciences and biology reproduce objects of knowledge based on natural and technical inputs (Haraway 1991,165), whereby a human such as Harbisson is on intimate terms with technology. Out of all three examples, he is the one that is most futuristic in that his very body can be seen to dispense with traditional boundaries to form new ones. For example, the technology does not fix his condition, but extends his other senses in ways that are imaginative and innovative and could be seen as revolutionary and something made purely of fiction.

A brief application of Haraway's cyborg imagery to the case of Mullins and Pistorius highlights several things. Both seize the tools (prosthetics) of their disabilities to 'mark the world that marked them as "Other"' (Haraway 2003, 33). Instead of embracing their differences as Harbisson does, they both do everything they can to break down socially excluding barriers that separate the normal from the abnormal. Within a world where disabled people are deemed as 'others', they are more widely accepted as okay because they are physically attractive and pleasing to the eye, augmenting their bodies to perform well. They both use the blades to enable themselves to be athletes, a prestigious career. The difference between them is that, as a model, Mullins is still seen as embracing who she is and is attractive, whereas Pistorius is only accepted if he does not actually win when he competes with able-bodied athletes (Mullins 2009; Swartz and Watermeyer 2008, 188). Thus the 'over-coming' of their disabilities is only acceptable if it still conforms to traditional notions of normal/ abnormal. Ultimately, if 'bionic' or 'super' bodies do better than normal bodies, the very hybridity of prosthesis and self, although celebrated by Haraway, is deemed unacceptable by society.

Next, I deliberately call the case study of Muliaga a forgettable cyborg because Haraway's imagery is best suited to those who choose to become one, as well to those who have the economic means to embrace the techno-rich culture that is undeniably brimming with possibilities to craft, change, enhance, or 'able' the disabled body if chosen. Whilst Haraway $(1991,155)$, writes about those 'others' who have been refused entry into acceptable social categories based on their different race, sex, or class she does not touch on the exclusion disabled bodies have experienced. Yet these are people who are often more noticeably dependent on technology to both survive and be accepted as functioning and thus worthwhile members of society. They are not granted the freedom promised 
by a redefinition of the self via a cyborg analogy. Rather, Thweatt-Bates (2012, 18) writes 'this dependence [on technology] is the flip side of their liberation... [and whilst] granted new freedoms, medical cyborgs are aware that this liberation is the result of a dependence on mechanism that cannot be ignored or denied. Whilst it is admirable to want to introduce cyborg imagery as an alternative to dominant, oppressive, and restrictive ideologies of the past it needs to become relevant and include discourses on how differently abled bodies may fit into the imagery. Whilst a fusion of flesh (Muliaga's body) and machine (oxygen purifier) does blur boundaries between where her body began and ended in terms of function, she did not take pleasure as a creature of new connections of organic and inorganic materiality.

IMPLICATIONS OF HARAWAY

When we seek to understand the implications of Haraway's cyborg imagery for disability studies, the theoretical position does offer new epistemological questions. These include how the idea of the cyborg, the fusion of both human and other, may change or impact how we think about what it means to be human. Also, relationships between bodies and technology/machinery become fluid and reflect an undefined existence, embodied with no fixed boundaries. Haraway's work is useful because it identifies that there are not absolute ways of ordering our knowledge of the world. She identifies that what a humanistic lens would qualify as a natural or normal body is actually naturalised by humans, meaning that it has been created as a truth as opposed to reflecting a reality. In this light, cyborg imagery is liberating by rejoicing in difference (Haraway 1991, 176), and celebrating the human being not as one confined notion but capable of existing in different forms. Here, Haraway's fractured identity analogy highlights that people are not solely definable by their impairments, which captures a nuanced view of humans, acknowledging that they are complex beings whose identities can be articulated in different ways. Further, according to Haraway $(1991,175)$, people whose social identity is literally written in their physicality or inability thus have the potential to rewrite their story. A testimony to this idea, Harbisson illustrates that an imaginative and futuristic image of a cyborg is certainly plausible.

Yet Harbisson is a unique example, and underneath the surface of this theory, the cyborg imagery fails to successfully displace all forms of 'hierarchal dualisms of naturalised identities' (Haraway 1991,175) and can create more divides. For example, a hierarchy of worth based on difference may be reinforced in a cyborg world. The inequality that would stem from some cyborgs being supe- 
rior to others in capabilities is a legitimate concern that emerges when Haraway's imagery is interrogated with three very different disabled bodies. When the variables of alteration or change are explored, it highlights that boundaries of social inclusion are not always the same each time. Boundaries remain, expanding or constricting, depending primarily on economic status and who can access 'high-tech' technology, as opposed to those who cannot. Harbisson has been involved in expensive and experimental treatment. Mullins and Pistorius are athletes, and their talent ensures sponsors and money. Muliaga on the other hand was poor and unable to pay for electricity to keep her oxygen purifier functioning, dying as a result. In this way cyborg theory cannot offer disability studies a practical lens because it fails to conceive of the specific material disadvantage that reinforces boundaries. By this I mean that the techno-rich and the techno-poor are reconstructed into a similar dichotomy. We only have to consider the unequal power relations that exist between first and third world countries that will undoubtedly continue with any increase of techno-fixes (Campbell 2009, 70).

One concern is that Haraway's $(1991,150)$ cyborg imagery rests on a utopian tradition of conceiving of a world without the influence of oppressive inequalities (e.g., gender, social, economic). Such a utopia, whilst it celebrates difference, appears to offer no place for the many forgotten cyborgs such as Muliaga who do not hold the same attraction when their dependency on machinery to survive does not make them unique or socially interesting. This utopian world is a place where bodies that can be augmented and enhanced would be welcome but not where bodies still seen as incapable would exist. After this imagery is applied to the three cases, we can surmise that a hierarchy of superiority occurs.

Lastly, if we look only at the surface of Haraway's imagery, accepted cyborgs appear to be sexy, modern, and seeking pleasure in fusions, whilst Muliaga, the forgettable cyborg, is the reality for many. Indeed, when compared to Muliaga, Harbisson, Mullins and Pistorius are examples of cyborgs that fit more comfortably within an imaginative world that Haraway encourages us to embrace. However there is a point of difference that is substantial on closer inspection. Whilst Harbisson seeks pleasure in difference, Mullins and Pistorius demonstrate for them it is not an entirely comfortable concept. Their desire to be considered normal within the contexts mentioned highlights that whilst they attempt to transgress categories they do not do so in order to be considered cyborgs. The dichotomies are what they are physically putting into question, something that Haraway's cyborg theory does not fully achieve. 
BRUNO LATOUR

My second chosen theorist is Bruno Latour, a French sociologist and contributor to post-humanistic thinking with his Actor-Network Theory (ANT). Like Haraway (1991), Latour (2005) does not talk about disability, although he is different to her in that he does not provide us with an imagery already formed, such as the cyborg. Instead, principal concepts of Latour that are useful to understand what he may contribute to disability studies include the actor-network, agency, symmetry, mediator and intermediaries.

Latour $(1992,227 ; 2005,8)$ argues against the notion that we live in a world where the social already exists. Instead, the social is made up of the connections between people and things, whereby the world is continually assembled and reassembled. This occurs within the network, which can be imagined as a map of associations being made by traces that are left behind by actors (Latour 2005,71 ). Instead of a tangible thing, it is a concept that describes the energy and movement 'which through trail, traces, vehicles, the world is being assembled' (Latour 2005, 179). Actors or actants according to Latour $(2005,46)$ are any human/non-human entities that carry action, and from this vantage point, both humans and non-humans have capacity for agency or the potential to create change in the network. Without accompanied action, or traces of connections, there are no agencies, and if not actively modifying a network, they are not visible (Latour 2005, 52). An important concept to understand within this paradigm is that of symmetry which does not reflect a levelling out of agency within the network, whereby every actor has equal impact at any one time. Instead it highlights the potential for different actors to transport powerful change at different times, illustrating how inter-related humans are to the objects around them (Latour 2005, 63). Latour $(2005,39)$ also uses the concepts of mediators and intermediaries to describe the means or way the social is produced. The former is an actor that alters the meaning or elements of the action they are carrying, whilst the latter can be defined as associations that are essentially closed whereby they transport meaning without any transformation occurring (Latour 2005, 38). Important to note is that mediators can become intermediaries and vice versa within any given network.

It is this particular shift in thinking that places Latour's $(1994,794)$ theoretical paradigm in a post-humanistic arena because he decentralises the role of the human. Boundaries and binaries that are present under a humanistic framework are discarded simply because for Latour the 'social' is not separated from other associations such as biological organisms. It is important to note here that I believe Latour would presume that any study regardless of the topic 
would require a similar application of thought. This is because he does not take the social aggregate as his starting place for analysis but looks at how we come to believe what we do, as well as how we make our world.

\section{APPLICATION OF LATOUR}

As mentioned, Latour does not write about disability but his theoretical perspective and methodology are applicable to many subjects because of the very fact that he believes in moving away from categories and distinctions made within society about how things are. Instead, he would strip back what we think we know and look at how our worlds are made up and urge us to become accustomed to there being many shifting frames of reference in which actors assemble their world.

By not taking social aggregates as his starting place, Latour would not look at each case as a finished product, but focus more on how they become the people they are within the particular networks they are a part of. For example, for Harbisson the implanted device that allows him to hear colour is a powerful actor, as it is only when the technology is working that the mechanical eye picks up specific sound waves as it registers different colour. Yet, in this network Harbisson's neurological system has to collect the waves and first mentally carry the action of sound and then connect each to the corresponding colour. Without either actor, Harbisson's personal identity as a cyborg with this capacity to inhabit the world in a different way would not occur. This new sense demonstrates the weakness of boundaries traditional social scientists have naturalised, whereby Harbisson embodies both the technological (human-made) world as well as the biological (organic) one at once. From a Latourian perspective, Harbisson's capacity is similar to the way a person can acquire skills such as a sensitive nose in order to work as 'a nose', someone who distinguishes fragrances and smells as a job (Latour 2004, 207). Without the technology, Harbisson would not be able to hear colour, just as without the bottles of fragrance to practice with, a person's sense of smell may not become heightened. This demonstrates that whilst an analysis using Haraway would classify Harbisson as an elite cyborg, Latour would not assume him to be a unique case in comparison to everyone else.

Latour $(1994,794)$ argues that we cannot disengage ourselves from the objects or non-humans around us because our fate lies in the connections made between ourselves and other actors. For example, Mullins and Pistorius became successful sportspeople through performing the action of running, yet this would be impossible to achieve without the prosthetic legs they attach to their 
bodies. Their particular networks are intricate assemblages of interconnected actions between flesh and objects. Take away the legs and they are without the vehicles that make them successful athletes. Yet both runners are powerful actors because they must hone and sculpt their bodies, training them to a standard that gives them the capacity to be good at their jobs. As attractive sports people they gain media coverage, which I argue is another actor in their network. The media portrays them as sexy and this has become a marketable part of their identity alongside their capacity to run fast.

To help us appreciate his theory, Latour $(1992,229)$ writes that to imagine what an inorganic object does we can consider how a human actor would, or if they indeed could, undertake an action or function without that object. For example, in the third case study Muliaga inhabits a world where her oxygen purifier is a vital actor that transports action that gives her the capacity to breathe. Unlike Harbisson who extends his senses further, the network that Muliaga creates alongside her machine simply allows her to sustain life by keeping her lungs open. Therefore, the oxygen purifier is an extremely powerful actor because it is effectively transporting more respiratory action than her body is. This illustrates the relevance of Latour's concept of symmetry, signalling the varying degree of impact that any actor, human or nonhuman, may have within a network. For example, the object here (oxygen purifier) is modifying Muliaga's respiratory function more than her own body is. However the case also includes others who traced associations within her network that eventuated in her death, namely the power worker and company. By switching off her power supply the oxygen purifier stopped working and became inert, void of action and thus more visible within the network because of the breakdown in associations. It went from being a predictable intermediary whereby the input (function of pumping out air) was enough to define its output (aiding Muliaga to breathe), and transformed into a mediator whereby the action or association was destroyed.

IMPLICATIONS OF THE THEORY

By exploring the various parts of the assemblages of each case as Latour would, a clearer picture of what messages or features that may contain explicit implications for disability studies can start to emerge. Firstly, a Latourian perspective that decentralises the human as the only thing that can create or modify networks allows us to appreciate the role that objects can have in our lives. It rejects the idea that we can take technology or machines for granted because, as all three cases demonstrate, our identities and worlds are not closed categories and are impacted by more than our own actions. By moving away from 
a human-centric paradigm, all pre-conceived ideas of what the social actually is are displaced. This is relevant for disability studies because it rejects a humanistic tendency to classify disabled people as 'others' and abnormal. By equating a disabled body's relationship with technology to that of an ablebodied person's, we move away from discourses of abnormality. For example, in an article entitled 'Is choosing a prosthesis so different than picking a pair of glasses?' Aimee Mullins (2009) illustrates that for her, the legs that enable her to walk or run are a way she augments her body and is just the same as selecting a pair of glasses or other object that enables the user somehow to do things they could not do without it. The implication for this is that Latour does not create a pre-determined stigma of disability when he explores networks.

This point of view is reflective of how a Latourian approach would discern the agency that objects can have. Instead of placing one meaning on prosthetics, as something to 'enable' amputees to walk, and a lesser significance on glasses that one may require to read, for example, he would simply view the object as it modifies within the network. From this vantage point, when we explore Latour's $(2005,30)$ concept of symmetry, one object is not privileged over another but capable of having the same importance that humans have. For example, Harbisson's relationship to the device that is implanted into the back of his head is one of mutual reaction and response, whereby each actor within this network assembles and reassembles Harbisson's world. The same can be said for Pistorius and Mullins with their prosthetics as well as Muliaga with the oxygen purifier.

Yet some may argue that whilst we cannot disengage from the objects that act within our network, the question still remains of the validity of giving them the same capacity for agency. For example, Muliaga's case demonstrates that the power operator, working on behalf of the power company, was the one that disconnected the power supply and effectively switched the oxygen purifier off. Yet, instead of assuming that humans ultimately have control over machines and technology, Latour would be quick to argue that if we work through the traced associations, agency is not as simplistic. For example, a storm could have just as easily been the one to cause a power outage. A Latourian analysis demonstrates that agency occurs in different moments and each person's reality is not as simple in nature. The value of this is that we are encouraged to not pre-judge but explore the plausible realities that can exist in different networks as the case studies show.

Latour may be criticised for his lack of discussion around power dynamics in the course of flattening out networks to see how they are formed. However, al- 
though he begins from a place of neutrality this does not mean his theoretical position is apolitical. More specifically, by not pre-judging or pre-determining anything, Latour is less likely to assume anything or assign categories. It is important to remember that he would not begin with social aggregates and therefore we cannot presume to seek them out, but to first engage with the various actors. When this is done, what is plausible is that power inequalities can emerge or appear after the various elements in the network are uncovered. For example, placing the networks side by side, we are able to see how Harbisson has become what Haraway would term as a futuristic cyborg, with access to state of the art technology in order to not only change his body but to advance science. This is in stark contrast to how the power inequalities emerge out of Muliaga's network whereby she was techno-poor, meaning she did not have money to sustain her connection to the technology that kept her alive. This highlights specific implications for disability studies that include the power differences based on income as well as unique and interesting conditions being more socially acceptable.

\section{COMPARISON}

Both theorists demonstrate that posthuman thought is not reflective of one particular theory but rather a variety of perspectives that all attempt to understand the world where the human is no longer superior to others or separated from nature/animals/objects. What Haraway and Latour have in common is the way they articulate the relationship between humans and non-human entities in new ways that question the humanistic human-made categories of knowledge and binaries between the organic/inorganic, flesh/man-made and human/nonhuman. Additionally, if within humanism abnormal bodies are characterised as 'others', Haraway and Latour demonstrate that underneath the order lies hybridity and complexity that cannot easily be separated.

After interrogating each theory with the three cases, it is the third one of Muliaga that best uncovers the main strengths and weaknesses of each. The sad story of Muliaga and her dependency on the technology to sustain life fails to fit comfortably within Haraway's cyborg imagery. It still depicts her as an 'other', more inferior, cyborg because she is not futuristic, unique or beautiful, and her glimpse of fame came when the technology stopped working and she died. Even if it sits within posthumanistic thought, cyborg imagery still predetermines differences and boundaries, reinforcing hierarchies between different bodies. Thus although Haraway attempts to subvert the dichotomies that separate nature from culture, her cyborg theory reinforces a superior/inferior dualism. Latour is different to Haraway, as by way of his very radical move into 
abstraction he does not give binaries any recognition or value, thus putting the place of dichotomies themselves into question. By not presupposing anything as being truth, and in starting from the place of no assumptions or certainties, information that we may take for granted is given attention. Thus a Latourian application illustrates that if they exist, power inequalities can emerge from networks instead of being assumed at the beginning.

Additionally, by moving completely away from the pre-requisite that a human is important within any network, this exploration of objects as actors is a relevant dialogue to engage with because it is already being explored in various ways within disability discourse. For example, a Latourian perspective would complement the questions researchers are engaging with regarding how disabled bodies relate to objects or devices that enable them to function better, particularly whether objects are merely 'things' or have more meaning (Campbell 2009, 52).

\section{CONCLUSION}

On the surface the theoretical paradigm of posthumanism has commonalities with disability studies because they both deal with issues of how 'others'/abnormal in society are constructed and treated. Both Haraway and Latour argue against an object/subject, culture/nature split because in separating ourselves from the machines or environment in which we live, we become alienated and disconnected. Yet although Haraway's writing engages with the possibilities that emerge when we no longer live within bounded traditionally constructed spaces and categories, it still is restrictive. For example, one potential problem is that whilst it has validity in the ways that it expands the concept of what it is to be human in a techno-culture, it may not fully disperse the negative discourses that surround disabled bodies when we conceive of them in terms of cyborg imagery. When all three cases are considered side by side, Muliaga's is a warning that whilst we can all be classified as cyborgs, some are inferior to others. Additionally, instead of rejecting categories completely, boundaries simply extend to encompass what may be accepted or rejected within this cyborg world of imagination and fiction. Once interrogated, humanistic categorisation based on difference is reproduced. On the other hand, Latour's methodological approach is radical in the sense that by displacing the idea of agency as being something only humans have, the dichotomies previously used to separate them are blurred and lose value. By deliberately not taking anything for granted we are able to move away from previously created categories of difference. By not exploring the networks of associations with any preconceived ideas, disabled people are thus not regarded as any different to 
able-bodied. This does not equate to ignoring inequalities that disabled people may experience, particularly when they may struggle economically such as Muliaga. On the contrary, although Latour may start off from a position of neutrality, power dynamics have the capacity to emerge from networks without recreating any divides that reinforce humanistic notions of normal/abnormal.

\section{NOTES}

1 By using the terms 'disabled people' and 'disabled bodies', my aim is to signal and critique the pervasive discourse that separates able-bodied members of society from those bodies that are deemed incapable, deviant, or different because they diverge from a secure notion of wholeness, humanness, and thus normalcy (Norman and Moola 2011, 1265).

2 Ferguson and Nusbaum $(2012,70)$ write about the ambiguity of the term 'disability studies' despite its expansion and currency within scholarship over the past two decades.

3 However the term does not have exclusivity, and has been used in 'anti-human constructions' found for example in the character of Borg in Star Trek: The Next Generation, or Arnold Schwarzenegger's 'Terminator' (Graham 2004). For more scope on the varying and at times opposing strands of posthumanism, see Thweatt-Bates (2013), Wolfe (2010), Castree and Nash (2006) and Krueger (2005).

4 According to Waters $(2006,50)$, we cannot know what the 'posthuman' is because 'no such creature yet exists, and there is little consensus among those who speculate on its emergence'.

5 I deliberately use the term 'forgettable' to provoke discussion when comparing her case to the others I use. However I am aware that rather than being a forgettable case, Muliaga's story has promoted discussions on the process of decisionmaking about electricity cut offs without checking circumstances of the clients.

\section{REFERENCES}

Braidotti, Rosi. 2006. 'Posthuman, All Too Human towards a New Process Ontology’ Theory, Culture \& Society 23 (7-8): 197-208.

. 2013. The Posthuman. Cambridge, MA: Polity.

Brisenden, Simon. 1986. Independent Living and the Medical Model of Disability'. 
Disability, Handicap \& Society 1(2):173-178.

Campbell, Fiona Kumari. 2009. Contours of Ableism. Basingstoke: Palgrave Macmillan.

Castree, Noel, and Catherine Nash. 2006. 'Posthuman Geographies.' Social \& Cultural Geography (7/4):501-2.

Crincoli, Shawn M. 2011. 'You Can Only Race If You Can’t Win? The Curious Cases of Oscar Pistorius and Caster Semenya.' Texas Review of Entertainment Sports Law 12(2):133-187.

Crow, Liz. 1996. 'Including All of Our Lives: Renewing the Social Model of Disability. In Encounters with Strangers: Feminism and Disability, edited by J.Morris, 206-226. London: Women's Press Ltd.

Ferguson, Philip M, and Emily Nusbaum. 2012. 'Disability Studies: What Is It and what Difference Does It Make?'Research and Practice for Persons with Severe Disabilities 37 (2): 70-80.

Foucault, Michel. 1970. The Order of Things. New York: Vintage.

Goodley, Dan. 2011. Disability Studies. Thousand Oaks, CA: Sage.

Graham, Elaine. 2004. 'Post/Human Conditions.' Theology and Sexuality 10 (2):10-32.

Griggs, Jessica. 2009. ‘Two Legs Good, 24 Legs Better' New Scientist 204 (2728):30-31.

Haraway, Donna. 1991. Simians, Cyborgs, and Women: The Reinvention of Nature. London: Free Association Books.

. 2003. The Haraway Reader. New York, NY: Routledge.

Harbisson, Neil. 2012. 'The Sounds of Scarlet.' New Scientist 215 (2877):50-50.

Herndl, Diane,Price. 2002. 'Reconstructing The Posthuman Feminist Body: Twenty Years after Audre Lorde's Cancer Journals.' In Disability Studies: Enabling the Humanities, edited by B. Brueggemann, R. Garland-Thomson and S. Snyder, 144-155. New York: MLA Press.

Johnson, Greg. 2013. 'Overcoming Obstacles is Normal for Aimee Mullins.' NCAA 
News. Accessed 28 October 2015 http://www.ncaa.org/about/resources/ media-center/news/overcoming-obstacles-normal-aimee-mullins/

Krueger, Oliver. 2005. 'Gnosis in Cyberspace? Body, Mind and Progress in Posthumanism.' Journal of Evolution and Technology 14 (2):55-67.

Latour, Bruno. 1992. 'The Sociology of a Few Mundane Artifacts.' In Shaping Technology/Building Society, edited by W.E. Bijker and J. Law, 225-258. Cambridge, MA: MIT Press.

- 1993. We Have Never Been Modern. Cambridge, MA: Harvard University Press.

- 1994. 'Pragmatogonies: A Mythical Account of How Humans and NonHumans Swap Properties.' The American Behavioral Scientist 37 (6):791-808.

- 2004. 'How to Talk About the Body? The Normative Dimension of Science Studies.' Body \& Society 10 (2/3):205-229.

-2005. Reassembling the Social: An Introduction to Actor-Network-Theory. Oxford: Oxford University Press.

Linton, Simi. 1998. Claiming Disability: Knowledge and Identity. Nyu Press.

Longman, Jeré, Peter Kiefer, and Joshua Robinson. 2012. 'Oscar Pistorius Makes Historic Olympic Debut.' O\&P Almanac 61: 9.

Marx, Karl, and Friedrich Engels. 1976. The German Ideology. Moscow: Progress Publishers.

Michalko, Rod. 2002. The Difference that Disability Makes. Philadelphia, PA: Temple University Press.

Mullins, Aimee. 2009. 'Is Choosing a Prosthesis so Different than Picking a Pair of Glasses?' 6 October 2013. http://gizmodo.com/5401408/is-choosing-aprosthesis-so-different-than-picking-a-pair-of-glasses

Norman, Moss .E and Fiona Moola. 2011. 'Bladerunner or Boundary Runner'?: Oscar Pistorious, Cyborg Transgressions and Strategies of Containment.' Sport in Society 14 (14):1265-1279. 
Oliver, Mike. 1993. 'Re-defining Disability: A Challenge to Research.' In Disabling Barriers - Enabling Environments, edited by J.Swain, V. Finkelstein, S. French, and M Oliver, 61-67. Thousand Oaks, CA: Sage.

Quinlan, Margaret M., and Benjamin R. Bates. 2007. 'Bionic Woman: Gender, Disability and Cyborgs.' Journal of Research in Special Educational Needs 9(1):48-58.

Shakespeare, Tom, ed. 1998. Disability Reader: Social Science Perspectives. London: Bloomsbury Academic.

Shildrick, Margrit, and Janet Price. 1996. 'Breaking the Boundaries of the Broken Body.' Body \& Society 2 (4):93-113.

Silvers, Kate. 2012. Oscar Pistorius: The man, the athlete. Palaestra 25(4):32-36.

Swartz Leslie, and Brian Watermeyer. 2008. 'Cyborg anxiety: Oscar Pistorius and the Boundaries of What it Means to be Human.' Disability \& Society 23(2):187-190.

Thacker, Eugene. 2003. 'Data made flesh: Biotechnology and the Discourse of the Posthuman.' Cultural Critique 53(1):72-97.

The NZ Herald. 2007. 'Mercury and Family Disagree Over Power Cut Death.' May 3o. http://www.nzherald.co.nz/nz/news/article.cfm?c_id=1\&objectid $=10442627$

Thweatt-Bates, Jeanine. 2013. Cyborg Selves: A Theological Anthropology of the Posthuman. Aldershott; Hampshire: Ashgate Publishing Ltd.

Vainshtein, Olga. 2012.' I have a Suitcase Just Full of Legs Because I Need Options for Different Clothing: Accessorizing Bodyscapes', Fashion Theory: The Journal of Dress, Body \& Culture 16 (2):139-170.

Waters, Brent. 2013. From Human to Posthuman: Christian Theology and Technology in a Postmodern World. Farnham, Surrey: Ashgate Publishing Ltd.

Wolfe, Cary. 2010. What is Posthumanism? Minneapolis: University of Minnesota Press. 